\title{
Application of Forensic Engineering
}

\author{
Vidanapathirana $\mathbf{M}^{1}$, Dahanayake $\mathrm{KS}^{2}$, Amararatne RRGS \\ ${ }^{1}$ Senior Lecturer, ${ }^{2}$ Senior Registrar, ${ }^{3}$ Registrar, Department of Forensic Medicine, Faculty of Medicine, Galle.
}

e-mail address of the corresponding author, Dr. M. Vidanapathirana: mudithavidanapathirana@yahoo.co.uk

\section{Introduction}

Forensic Engineering is a recognized and important aspect in forensic investigations. Forensic electrical engineering is a branch of forensic engineering, and is concerned with investigating electrical failures and accidents in a legal context. The case under discussion is an example where the Judicial Medical Officer sought the services of forensic electrical engineering to ascertain the cause and manner of death.

\section{Case report}

A 25 year-old manual worker of apparently good health who worked in a table salt manufacturing factory was found dead beside an old metal blower (Figure 1) with a highly corroded metal covering. At the autopsy a dry burn injury over the right elbow was found. It was an elongated, well demarcated, groove like, second degree dry burn mark, measuring $7 \mathrm{~cm} \times 1 \mathrm{~cm} \times 0.2 \mathrm{~cm}$. It was placed vertically on the postero-lateral aspect of the right elbow. It had a pale crater, containing burned and charred tissues. Both its margins were elevated as a ridge measuring 1-2 $\mathrm{mm}$. The skin of the immediate surrounding area appeared mildly red. There were six separate punctuate burns ranging from $0.2 \mathrm{~cm}$ to $0.5 \mathrm{~cm}$ by the sides of the injury within $1 \mathrm{~cm}$ distance on each side (Figure 2).

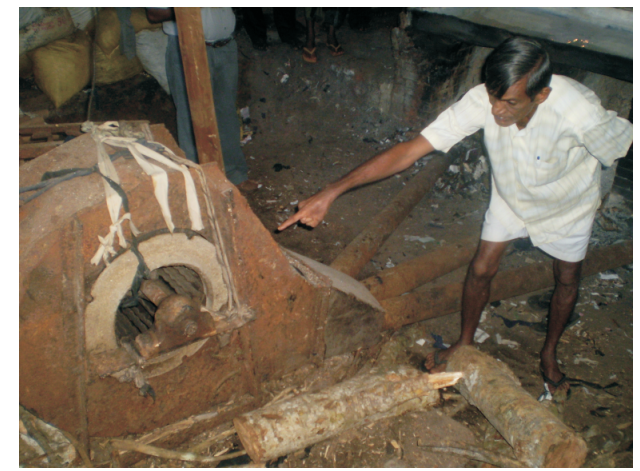

Figure 1 - The old metal blower and the probable site of impact

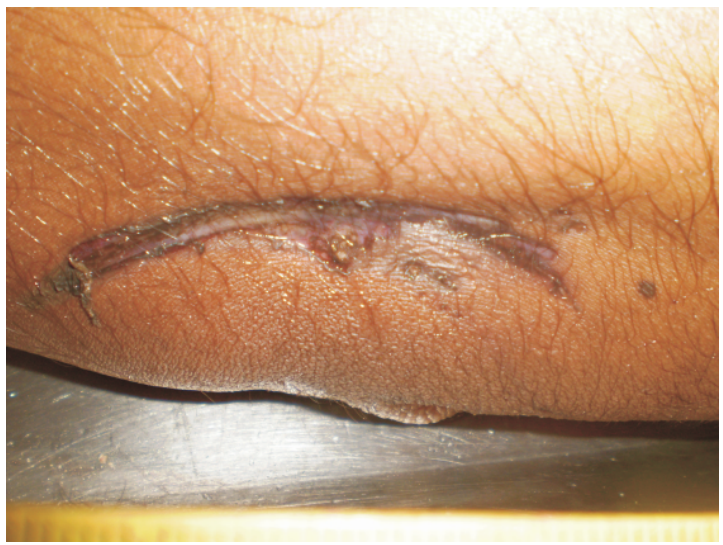

Figure 2 - An elongated, dry burn mark, on the back aspect of the right elbow joint.

The pale crater, elevated ridges at the margins, surrounding satellite spark burns ${ }^{1}$ and histopathological evidence of nuclear and cellular pallisading of basal epidermal cells and, dermoepidermal separation with formation of vacuoles ${ }^{2}$ were suggestive of an electrocution injury (Figure 3).

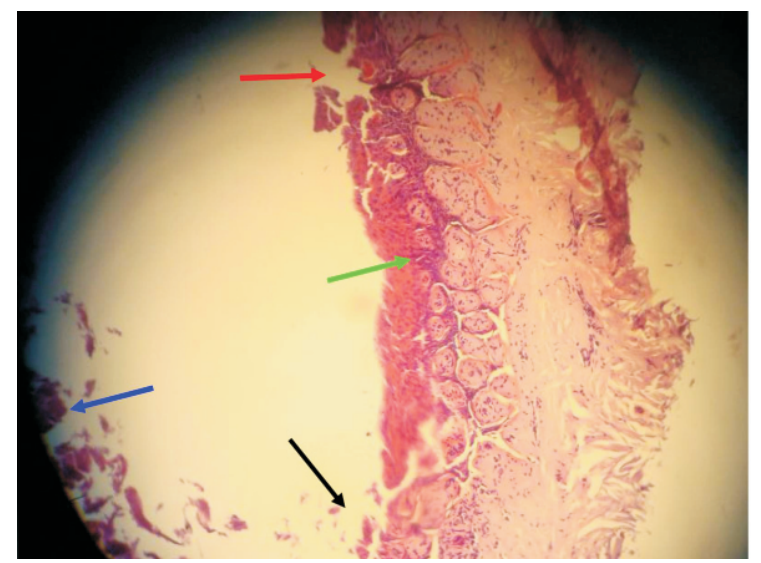

Figure 3 - A photo micrograph showing sloughed off keratin layer (black arrow), discontinuation of the epidermis (red arrow), charring of the skin (Blue arrow), formation of intra-epidermal blisters and nuclear and cellular palisading (Green arrow) of the basal layer of the epidermis. Dermal blood vessels are congested. 


\section{Discussion}

Due to the reasonable suspicion as to the safety state of the blower, the opinion of the area Government Electrical Engineer was obtained through the Inquirer into Sudden Deaths. According to the engineer, the insulation between the blower and its metal covering had been weakened due to the effect of the moisture mixed with highly salty environment. Therefore, if a person had got contacted with the metal covering, he would have had a fatal electric shock. The size and the shape of the injury were compatible with the shape of the conductor (i.e. corner edge of the metal covering).

Presence of an apparently defective electrical blower with its corroded metal covering with the victim's body in close proximity to the apparatus, the compatibility of the site of the injury when the victim was standing with the height of the covering from the floor and the compatibility of the injury with the shape of the conducting surface were suggestive of electrocution. This is further supported by the fact that at the time of injury victim had not being wearing slippers or shoes and the surrounding being a salty environment which facilitated grounding. The satellite burns could have been due to surrounding sparking between the conducting surface and the skin at the time of electrocution ${ }^{3}$. These features further supported an electrocution injury.

The objective of the investigation by the electrical engineer is when an electrical fault or unreasonably hazardous electrical system causes an electrical injury the party responsible for the electrical accident can be the target of insurance subrogation or an injury lawsuit ${ }^{4}$. Though we do not have designated forensic engineers, we used to summon the area Government Electrical Engineer through the inquirer into sudden deaths for his opinion.
The application of forensic engineering was mandatory in this case, to ascertain the final cause and manner of death. The forensic pathologist cannot give opinion regarding the possible defect in the apparatus as the field of electricity is a separate disciplinary, which is beyond his perimeter of expertise.

The case under discussion was selected as it was a landmark case where the cause and the circumstance of death, i.e. accidental electrocution, was concluded by considering both the pathological evidence as well as the scientific evidence offered by an independent electrical expert regarding the possible defect in the electrical appliance. The case also highlights the importance and the mandatory requirement of the scene visit. Furthermore, the next of kin of the deceased would be eligible to claim workmen's compensation, as there was a very high probability of death due to obviously reparable or replaceable defect in the old and ill-maintained electrical appliance.

\section{References}

1. DiMaio VJ, DiMaio D. Forensic pathology. $2^{\text {nd }}$ Ed. Florida: CRC, 2001: 409-14.

2. Polson CJ, Gee DJ, Knight B. The Essentials of Forensic Medicine, $4^{\text {th }}$ edition, New York: Pergamon Press, 1985.

3. Spitz WU, Spitz and Fisher's Medico-legal Investigation of Death. $4^{\text {th }}$ Ed. Illinois: Charles C Thomas, 2006: 882-95.

4. Forensic Electrical Engineering. Wikipedia; the free encyclopedia. www.wikipedia.org Accessed on 2009/06/15. 